\title{
SOBRE LA REDENCIÓN POPULISTA Y LA FUERZA CONSTITUCIONAL: EL VALOR INTANGIBLE DE LA DEMOCRACIA
}

\section{On constitutional power and populist redemption: The intangible value of democracy}

\author{
JOSÉ ANTONIO SANZ MORENO \\ Universidad Complutense de Madrid \\ jasanzmo@ucm.es
}

Cómo citar/Citation

Sanz Moreno, J. A. (2019).

Sobre la redención populista y la fuerza constitucional:

el valor intangible de la democracia.

Revista de Estudios Políticos, 183, 161-190.

doi: https://doi.org/10.18042/cepc/rep.183.06

\section{Resumen}

Los diferentes significados de populismo no hacen sino certificar la necesidad de redefinir la democracia. Y aquí no valen los plañideros: el populismo ha vuelto para quedarse. Por eso debemos esclarecer sus «razones»; y — desde la izquierda posmarxista - nada mejor que contrastar la obra de Laclau y Mouffe. También el repaso a las diferentes maneras de entender los movimientos populistas nos permitirá asomarnos a su construcción del pueblo frente al antipueblo. Pero será el constitucionalismo el que nos resuelva la paradoja de la democracia: de un lado, poder popular absoluto; de otro, gobierno para los integrantes del pueblo y, con ello, límite jurídico al ejercicio del poder. De poco sirve decantarnos por una concreta definición del populismo (ideología blanda, discurso, estrategia política, patología), pero sí cabe observar su simbiosis con la democracia. Y, precisamente, con la máxima vox populi, vox dei, la redención populista se convierte en su enemigo más mortífero. Desde aquí, el populismo o se reeduca con su anclaje constitucional en la dignidad de la persona y en el rule of law, o desde la totalización popular del poder y su encarnación personalizada, la democracia tiene los días contados. 


\title{
Palabras clave
}

Populismo; soberanía popular; democracia constitucional; cláusulas de intangibilidad; Estado de derecho.

\begin{abstract}
The different definitions of populism do nothing if not reinforce the need to redefine democracy. Populism has returned to stay, so it is necessary to analyze "populist reason"; and from the post-Marxist perspective this means the work of Mouffe and Laclau. A review of different ways to understand populist movements is also imperative to confront the fiction of one 'People' versus the real and plural population. However, constitutionalism will be our answer to resolve the democratic paradox: on the one hand, popular power is absolute; on the other hand, government by and for the citizenry and, with it, legal limit to the exercise of power. Nowadays, it is not a good idea to seek a new definition of populism (soft ideology, discourse, political strategy, pathology), but we need to condemn its symbiosis with democracy as vox populi vox dei. Populism is not the redemption of democracy, but its worst enemy. So, we have two alternatives: either populism is redirected through its constitutional anchoring in individual human dignity and intangible rights, or the unlimited power of the people and its totalitarian embodiment will mean that the democracy's days are numbered.
\end{abstract}

\section{Keywords}

Populism; popular sovereignty; constitutional democracy; intangibility clauses; rule of law. 


\section{SUMARIO}

I. ¿̇CÓMO GOBERNAR LA DEMOCRACIA? PUEBLO, CONSTITUCIÓN Y PODER. II. SOBERANÍA POPULAR ILIMITADA: ALTA TRAICIÓN A LA DEMOCRACIA. III. RETÓRICA POPULISTA, O CUANDO EL SIGNIFICANTE PUEBLO DEVIENE DECONSTRUCCIÓN DEMOCRÁTICA. IV. EN DEFENSA DE LA DEMOCRACIA INTANGIBLE. BiBLIOGRAFía.

\section{I. ¿̇CÓMO GOBERNAR LA DEMOCRACIA? PUEBLO, CONSTITUCIÓN Y PODER}

La democracia interpela al quién de un pueblo formado por individuos de carne y hueso. Por eso definir el demos ${ }^{1}$ siempre ha sido tan complicado como resolver el salto de la identidad entre gobernantes y gobernados a su manifestación representada ${ }^{2}$.

Contra las guerras de religión y favorable al absolutismo, Hobbes nos dibujó el camino (Ryan, 2012: 411-451). La distinción entre people y multitude: el uno, con su propia voluntad convertida en acción; los muchos, con voluntades diversas y acciones plurales (Canovan, 2005: 97-99). Los individuos — en masa — son multitud; en cambio, el rey —identificado con el pueblo- encarna su representación, es decir, su propia voluntad y sus acciones se muestran como si fueran voluntad popular.

Pero abandonados los reyes, con el cambio de la legitimidad divina a la inmanente de la democracia, la pregunta —-más allá del quién— se concentra en si el pueblo - compuesto por individuos (diferentes) que se dicen ciudadanos (iguales) - tiene capacidad plena de expresar una única voluntad y actuar como un solo sujeto político. En pocas palabras, vuelve a resonar la cuestión definitoria: ¿el poder, en democracia, es total e ilimitado?

1 Demos como sujeto colectivo y volitivo y, con ello, titular del poder y con capacidad de ejercicio.

2 "El concepto del "demos", es decir, el conjunto de las personas que es considerado sujeto del poder político [...] ya no se discute que tenga que ser universal [...]. Lo que se discute ahora es cómo instrumentar su nivel de participación en la deliberación de los asuntos públicos, más allá de la intervención en las elecciones periódicas de los representantes» (Abellán, 2011: 296). 
Para su respuesta, la titularidad del poder también debe ejercitarse. De ahí nace la antinomia entre identidad y representación o, en otros términos, la relación entre el pueblo y sus gobernantes, entre la voluntad popular y la de los que dicen manifestar su voluntad. Con la representación, el ausente (el pueblo soberano) se hace presente: el Parlamento es el órgano tangible (reunión colegiada de los representantes del pueblo) de un sujeto indeterminado (la masa de individuos) que adquiere forma y capacidad volitiva de acción. La soberanía política del pueblo (poder constituyente), con la constitución y su respuesta parlamentaria, se convierte en la ordenación legal de sus representantes (poderes constituidos). La titularidad del poder y su expresión constitucional se conjugan en su ejercicio ordinario por un gobierno representativo: el imperio del pueblo, etimología de la democracia, se resuelve en forma parlamentaria. La democracia se adjetiva como representativa y la titularidad del poder se ejerce a través de sus representantes.

Esta conjunción «milagrosa» entre ausencia y presencia de un sujeto indeterminado que se autodetermina, de un espacio desorganizado, sin forma y sin ordenación, que construye un orden y lo colma de Derecho (con mayúsculas) — delimitando obligaciones y derechos (subjetivos) — envuelve la ficción de la representación. El Parlamento presenta -institucionalmente- lo «no presentado». El pueblo soberano muta de muchos en uno, de innumerables voluntades a una única voluntad: la decisión del Gobierno parlamentario es la voluntad popular. Sin embargo, la representación política —en su traslación de la soberanía popular al Parlamento- ¿se llena tanto como para proclamar que el pueblo solo se expresa a través de sus representantes? En un Estado de partidos que se sostiene a duras penas, la crisis recurrente de la modernidad entre teoría y práctica de la democracia se confirma, ahora, como nueva revuelta "popular» definitoria.

La democracia se califica, principalmente, como representativa, pero este mandato no colma toda su significación: el pueblo retiene otras formas de expresión, de reservas de poder, no indirectas o representativas, sino directas o participativas, es decir, que visibilizan al pueblo como unidad pública de decisión y acción. La democracia representativa deja sitio a lo que Schmitt llamó el legislador extraordinario ratione supremitatis: el pueblo ejercita su poder supremo y determina el orden y el derecho. En la carrera populista por el empoderamiento ciudadano, el pueblo toma una decisión, vía referéndum, cuando una mayoría de votos ha decantado hacia un lado la balanza. Pero algunos referéndums los carga no dios, sino el diablo, y, al igual que las elecciones, se realizan de muy diversas formas: no todas democráticas. Votar es democracia, pero la democracia no se agota votando. En cambio, el consentimiento del pueblo se ha convertido, desde hace más dos siglos, en la única forma de legitimar el poder (Canovan, 2005: 1, 108-110). Cada victoria 
electoral se presenta como mandato popular, cada referéndum, como expresión inequívoca del trivializado derecho colectivo a decidir; y, por ello, todo desvío institucional es un quebrantamiento del poder del pueblo o la usurpación de su voluntad.

Aquí es donde nos dimos de bruces, especialmente en Occidente, tras la Gran Recesión económico-financiera de 2008 y su conversión en terremoto político-institucional, con la parálisis del modelo posbélico de partidos y la «explosión populista» (Judis, 2016). A pesar del pacto constitucional como límite al poder, la teoría de la democracia se topó con el pueblo como sujeto colectivo, vivo y volitivo, y, con ello, el uso retórico y vacío de un concepto tan ambiguo permitió fraguar la línea divisoria con el «no-pueblo» y asaltar — desde el suelo- los cielos. Desde abajo, los movimientos populistas, en su identificación de la parte (líderes populistas y sus adláteres) con el todo (el pueblo como fuente única de legitimación), emprendieron la lucha por el poder hegemónico y la democracia abrazó, otra vez, su acepción más teológica.

La democracia siempre ha tenido que redefinir el sujeto titular del poder y sus valores. Desde los orígenes griegos, con su respuesta directa, o en la modernidad republicana, como conversión representativa y nacional, el pueblo - en permanente tensión entre la libertad de los antiguos y la de los modernos- afrontó sus espacios, límites y desbordamientos (Ryan, 2012: 946-977). La incertidumbre de la democracia —entre correcciones formales y definiciones sustantivas, entre ontologías ilimitadas del poder frente a deontologías de límites materiales, etc.- es la herida doctrinal de una guerra política de la que no podemos zafarnos. Con nacionalistas, populistas y nacional-populistas nos escoraremos hacia una formulación democrática desde la absolutización del titular del poder -el pueblo sin freno alguno, como nueva divinidad de una voluntad omnipotente-; en cambio, desde la revisión constitucional, nos posicionaremos dentro de un Estado de derecho con la constitución como límite al poder (también del pueblo en democracia). La retórica volitiva del pueblo, como poder constituyente ilimitado, colisionando frontalmente con su conversión jurídica en norma fundante y suprema (ciudadanos y poderes públicos ya constituidos siempre sujetos al orden constitucional).

Así aparecen dos presupuestos de reconciliación improbable: por el lado de la fe de muchos nacionalistas, populistas y confluencias, la concepción religiosa de la política y su voluntad popular todopoderosa; por el lado de los agnósticos o no creyentes, pesimismo antropológico y escepticismo ante el poder, y, de ahí, sus contrapesos para limitarlo mediante el rule of law y la dignidad de las personas. El combate entre, de un lado, irracionalidad politica, voluntad colectiva univoca y pasiones, y, de otro, lógica jurídica, pluralidad volitiva y control institucional ha estallado de nuevo; y, aunque la contienda se sabe 
interminable, cabe firmar algún armisticio que la haga más civilizada y permita la "conllevanza». Este será el objetivo fundamental de nuestro artículo.

Desde aquí, las dos caras de la democracia de Margaret Canovan — pragmatic («ballots, not bullets») o redemptive («vox populi vox dei»; 1999: 9-10) — son ejemplo palmario de las contradictorias definiciones de un concepto tan cargado de historia como repleto de buenas intenciones y mucha demagogia. Precisamente, uno de los dogmas más recurrentes de la democracia absolutista es mantener que «instalado el pueblo en el poder, todo irá bien» (ibid.: 12), como si — por arte de demiurgo y desdeńando el desastre ateniense en Siracusa - con la sola apelación al gobierno popular cualquier mal pudiera ser evitado o resuelto.

La dualidad política de la democracia entre la titularidad del poder y su ejercicio, entre la soberanía popular y su representación, entre sujeto y objeto del poder, será una aproximación más o menos alejada de la realidad y siempre precisará de su mutación normalizada, es decir, normas e instituciones, decisiones y personas jurídicas, en definitiva, ordenación constitucional. Resuelta la excepción, duerme el soberano y reina la normalidad de unos poderes sometidos al derecho. Pero la dicotomía poder constituyente/poderes constituidos produce monstruos; o, como afirma Zanatta, «en todas partes subsiste la tensión innata de toda democracia entre "el pueblo" y sus representantes" (2015: 166)³. De ahí la fusión de la doble naturaleza de la democracia: de un lado, la conversión de la autodeterminación personal en dimensión jurídico-constitucional, como límite al poder (constituyente), distribución de poderes (constituidos), actualización del derecho (objetivo) y garantía de derechos (subjetivos, individuales y de transacción mayorías/ minorías); de otro, la respuesta de la autodeterminación colectiva en cuanto dimensión politica, como sublimación del pueblo en su fundamentación del poder, de su titularidad (original) y ejercicio (normalizado).

La paradoja democrática (Mouffe, 2000) envuelve la irresoluble antinomia entre identidad y representación: de un lado, la identidad como igualación de gobernados y gobernantes, en un sistema estatal que solo puede tener legitimidad si es democrático, es decir, si el gobierno-poder lo detenta el pueblo (en singular) como todo volitivo; de otro, la representación política como manifestación de lo ausente, es decir, del pueblo, que de todo unitario pasa a parte, de la titularidad del poder a su ejercicio por sus representantes, que for$\mathrm{man} /$ determinan lo informe/ indeterminado ${ }^{4}$.

3 Estudio empírico de la democracia en setenta países, trabajando cien indicadores, desde 1990 a 2014, Merkel y Bochsler (2016).

4 Y, sin embargo, a pesar de su «democracia de identidad», con la representación más absoluta de Schmitt se hace visible lo invisible (Rasch, 2016: 328-329): lo oculto se muestra personal, vivo y coceando. 
En la confluencia de ambos conceptos —identidad y representación-, la soberanía popular se convierte en institucionalización estatal, pero, a pesar de metamorfosis tan kelseniana (de mi voluntad hecha ley al orden coercitivo que la constriñe), la autodeterminación colectiva no puede subyugar enteramente la libertad del individuo, es decir, la alícuota de autodeterminación del ser humano en democracia.

\section{SOBERANÍA POPULAR ILIMITADA: ALTA TRAICIÓN A LA DEMOCRACIA}

Por eso, más que hablar de distintas tradiciones, tal y como plantea Chantal Mouffe (2016a), que amparan — a su manera - la democracia, urge resolver cuándo nos hallamos ante la auténtica traición que la pervierte.

La democracia no es ningún híbrido de dos enfoques - incompatiblesque coexisten, renqueantes, en la historia: de un lado, gobierno/poder del pueblo y su traducción en soberanía/voluntad ilimitada; de otro, la concepción liberal/constitucional en su expresión como límite al poder y equilibrio entre poderes 5 . ¿Gobierno del pueblo contra imperio del derecho? Canovan responde tajante: el rule of law es la fuerza y el valor de la democracia (2005: 83-85), no un instrumento de usar y, cuando se nos antoje, tirar.

Considerar los dos vectores democráticos como antitéticos y divergentes conduce a una comprensión errónea de la democracia, tan asesina como suicida. Con una determinación unidireccional de la democracia, que circunscribe su sentido a la voluntad popular, ilimitada e ilimitable, el rule of the people colisiona con el rule of law $\mathrm{y}$, en este choque de legitimidad (original) y legalidad (derivada), la democracia tiene las de perder $^{6}$. De ahí que la

5 Descripción de la historia de la democracia moderna como dos tradiciones contradictorias, que debemos, definitivamente, rechazar: vertiente liberal (imperio de la ley, límite y separación del poder y garantía de la libertad y del pluralismo) versus dimensión propiamente democrática (soberanía ilimitada y prelación igualitaria) (Mouffe, 2000; 2012: 11-12; 2013: 123-124; 2016b; 2016c; «indeed, ultimately irreconcilable», 2018: 15; también, Monedero, 2017: 143).

6 Por eso criticamos una jurisprudencia del Tribunal Constitucional español, empeñada en confundir términos diferenciables como legitimidad y legalidad (ATC 24/2017, de 14 de febrero, FJ8), o que, pese a su defensa de la Constitución, se empecina en considerar nuestra democracia como "no militante» (STC 114/2017, de 17 de octubre, FJ5), cuando la democracia de todo Estado constitucional —expresa (sistema alemán, francés, italiano, portugués, etc.) o implícitamente (modelo español en la interpretación del art. 168.1 desde el art. 10.1) — es siempre —con mayor o menor 
democracia - forma singular, como gobierno (directo) del pueblo, pero también, delimitación material/constitucional como imperio limitado y protección de derechos - no debe radicalizar su titularidad original si no quiere poner en peligro su propia supervivencia.

La dualidad democrática — de un lado, mirando al pueblo y a la soberanía popular; de otro, creando ordenación y derecho(s) — no puede encauzarse como paradoja irresoluta que, en la tensión entre la idea etimológica (poder del pueblo) y la construcción jurídica (límite al poder), teologiza al pueblo como ser supremo, absoluto y sin trabas, para disolver la esencia material de la democracia, en cuanto protección del individuo frente a los abusos el poder y delimitación de sus derechos y responsabilidades. Con la sublimación de la forma (titularidad del poder) desaparecen los valores y fines en los que se asienta la democracia. El mito del pueblo - presente, actuante y todopoderoso (Canovan, 2005: 127) — sigue la estela de la transustanciación católica en la eucaristía: la multitud informe, tan ordinaria como el trigo y las uvas, se materializa milagrosamente en vox populi, vox dei: el dios terrenal que ordena, decide y actúa.

La tensión entre la búsqueda de la unidad y la realidad plural de la sociedad, entre el modelo teológico del poder omnipotente de un dios trascendente mutado en pueblo, se proyecta como identidad de gobernantes y gobernados. Y, sin embargo, su realización representativa ${ }^{7}$ como distinción entre los que mandan y los que obedecen y, con ello, control del poder para la salvaguarda del derecho (objetivo) y de los derechos (subjetivos y de las minorías), se reconduce desde el constitucionalismo democrático ${ }^{8}$. Este impone restricciones a la voluntad popular y, no obstante, para aquellos que propugnan una interpretación numérica de la democracia, cualquier restricción en el ejercicio de la voluntad popular sería antidemocrática (Stacey, 2016: 163).

La controversia está servida: ¿cómo colmar la laguna entre revolución y práctica constitucional, entre la presencia directa del pueblo y los límites al poder? La diferencia entre situación excepcional y normalidad política, entre revolución (participación popular inmediata) y su normatividad constitucional (de la soberanía constituyente a la práctica jurídica del sometimiento ciudadano y de los poderes públicos a los límites del rule of law), sale a nuestro encuentro. No obstante, el dilema entre democracialilimitada y constitucionalismo/sujeción se

contenido- militante, o deja de ser democracia «constitucional», es decir, también límite al poder desde los derechos inviolables, el respeto a los derechos de los demás y la sujeción al orden jurídico.

7 Vid. STC 103/2008, de 11 de septiembre, FJ2.

8 O democracia constitucional, en la formulación de Ferrajoli (2011: parte IV). 
diluye con la superación jurídica de la distinción entre poder constituyente y poderes constituidos.

El supuesto poder ilimitado del pueblo desaparece con su obra, la constitución; mejor todavía, duerme, o se extingue, en el sincretismo metodológico de un poder constituyente ya constituido. Desde aquí, la construcción constitucional sigue abrazada a su origen en la retórica de la soberanía popular ${ }^{9}$, pero atempera el sentido de esta y censura su conversión trascendente en poder omnipotente. La soberanía popular, cuya titularidad tiene el pueblo, se ejercerá de dos formas distintas: de un lado, y de forma excepcional (anormalidad política), a través del propio poder constituyente, creador de la constitución; y de otro, como hábito ordinario (normatividad jurídica), a partir de los poderes constituidos que representan a ese mismo pueblo.

La conjunción entre identidad y representación, entre poder constituyente (pueblo) y poderes constituidos (conversión popular en ciudadanos que participan en los asuntos públicos y los propios poderes públicos, sujetos al orden constitucional) ${ }^{10}$ se resuelve con la validez de la constitución (obra original del pueblo) y el desarrollo de su vigencia (actualización del poder popular). La supremacía constitucional anestesia al poder constituyente, que solo despierta como soberano ya constituido en sus atribuciones de reforma o revisión constitucional. Con todo, la distinción entre poder constituyentelabsoluto frente a poderes constituidos/limitados no puede ser tan radical como para imponerse a la propia determinación jurídica, desbordando el rule of law desde el rule of men en su identificación teológica como gobierno del pueblo.

Desde Kelsen, al menos, el propio constitucionalismo define el límite normativo al ejercicio del poder ${ }^{11}$. En el derecho constitucional - con sus manidas distinciones entre reforma y ruptura, continuidad y revolución- la diferencia entre una modificación constitucional y la destrucción del orden con la creación de una nueva constitución viene dada por la confluencia de un poder ya constituido que hace renacer al constituyente (reforma), frente a la existencia de un nuevo poder constituyente, tan total como para hacer brotar la constitución de la nada jurídica (Stacey, 2016: 167-168). Y, sin embargo, contra esta separación — propia del Schmitt absolutista de entreguerras—, desde un Estado constitucional anclado en el mundo de la ordenación internacional el vacío jurídico no existe (Sanz, 2013: 136-145; 2017: 139-142).

9 Ferrajoli cita algunas constituciones que así lo hacen, recogiendo también el art. 1 de la española, CE (2011: 13).

10 Arts. 1.2., 2, 9.1 y $23 \mathrm{CE}$.

11 De ahí lo absurdo de la analogía entre la omnipotencialilimitada de Dios y la soberaníal limitada del Estado (Kelsen, 2017: 18). 
Con Rousseau, pasando por Carl Schmitt, hasta llegar a los más renombrados teóricos del populismo - y, singularmente, el tándem Laclau y Mouffe, desde la izquierda posmarxista-, se nos sigue presentando la relación entre liberalismo/constitucionalismo, de un lado, y democracialmayoritarismo, de otro, como contradicción irresoluble. Reducida a dos ecuaciones (gobierno=poder y pueblo=voluntad mayoritaria ilimitada), la definición de la democracia desaloja lo jurídico de toda fundamentación en la dignidad de la persona y los derechos individuales, y a estos de todo nuevo iusnaturalismo como inalienables e imprescriptibles. Descrito desde la constitución, se reniega de cualquier cláusula de intangibilidad, $y$, por tanto, se identifica su sustancia fundamental con el procedimiento agravado para su reforma. Con la prelación del principio de mayoría en democracia y su reformulación como recuento de votos, la sentencia del absolutismo princeps legibus solutus convierte al pueblo en único e ilimitado poder, hacedor de todo el derecho y determinador de toda posición jurídica y de todos los derechos personales y colectivos, sin atadura alguna a las leyes que crea ${ }^{12}$. De ahí que la clave sea el pueblo y no la humanidad en la democracia de identidad de Carl Schmitt. El desprecio del jurista alemán a los límites impuestos a la voluntad popular le apartan no ya de la visión liberal de la democracia, sino de todo significado democrático que merezca tal nombre (Sanz, 2013: 118-128). Y, sin embargo, frente al universalismo liberal y sus derechos humanos, su distinción antagónica amigo/enemigo como concepto determinante de lo político, se reinterpretan, por Mouffe, como articulación hegemónica contingente en su presentación de la parte como el todo. Pero a pesar de este rescate-trampa, Schmitt, más que para hacernos comprender la naturaleza paradójica de la democracia liberal y su dualidad inclusión/exclusión (Mouffe, 1999, 2000), nos sirve para, definitivamente, romper con unos postulados de identidad nacional y de homogeneidad colectiva que ahogan todo pluralismo e impiden su realización democrática ${ }^{13}$.

12 «Ciertamente, se olvida a menudo que, mucho tiempo antes del siglo $\mathrm{xx}$, los hombres del mundo occidental aprendieron que la palabra "tiranía" podía ir asociada también al término "mayoría"; es decir, que en nombre de una mayoría conquistada en las urnas también era posible justificar el desprecio por las libertades y la destrucción de los derechos fundamentales» (Del Rey y Álvarez, 2017: 28-29). Con Ferrajoli: «La tesis que pretendo sostener es que esta caracterización solamente formal de la democracia no es suficiente para fundamentar una definición adecuada de ella y que, con tal fin, hay que integrarla con la indicación de algún vínculo de carácter sustancial o de contenido» (2011: 9). O, en forma de pregunta: ¿podría ser democrático un sistema en el que se decidiera por mayoría reducir o negar los derechos de las minorías y/o de los individuos?

13 Porque con Schmitt: «Se abre paso una concepción totalitaria del poder constituyente no sometido ni a leyes ni a procedimientos regulados jurídicamente» (Sauquillo, 
Aquí es donde la emancipación popular como poder ilimitado proyecta todo su peligro redentor. La conversión del adversario político en enemigo existencial coloca a los populistas en la secuencia teológica de privar a «los otros» de cualquier legitimación democrática (Zanatta, 2015: 255): de un lado, el «nosotros» de los populistas, en permanente construcción del pueblo; $\mathrm{y}$, de otro, el resto, que no pertenecen a la colectividad, o, de pertenecer formalmente a ella, la han vendido o mancillado, haciéndose merecedores de su expulsión y privándoles — por su deslealtad y/o degeneración — de su integración popular (extranjeros, refugiados, no asimilados, élites corruptas, etc., frente al pueblo, puro e inocente). No cabe lamentarse ni mirar para otro lado: el populismo - si es que se fue alguna vez- ha vuelto con renovadas fuerzas y, además, se expande en políticas públicas y en apoyo electoral y ciudadano. La disyuntiva es: o se domestica por el lado constitucional, como límite al poder, o se desborda, y, desde la totalización popular y la encarnación más personal, la democracia dejará — más pronto que tarde— de existir.

\section{RETÓRICA POPULISTA, O CUANDO EL SIGNIFICANTE PUEBLO DEVIENE DECONSTRUCCIÓN DEMOCRÁTICA}

«Un fantasma se cierne sobre el mundo: el populismo» (Ionescu y Gellner, 1969: 7). Casi cincuenta ańos después nos encontramos con aparecido arranque en otro libro: «Un estremecimiento sombrío recorre la superficie de Occidente bajo el nombre de "populismo" (Lassalle, 2017: 11). Lo que nos lleva a pensar que, entre espejos o espectros (Arditi, 2004; Panizza, 2009), fantasmas y monstruos (Ramírez, 2015), el populismo no es un fenómeno ni mucho menos novedoso (Canovan, 1981; Riker, 1982; Taggart, 2000), ni cabe desecharlo sin más miramiento (Krastev, 2011: 15). Su reconstrucción del pueblo soberano y su elogio a la voluntad popular nos retrotraen a escenarios del siglo Xx tan transitados como cargados de guerras y holocaustos: el problema de la total identificación de los ciudadanos con sus gobernantes puede conducirnos a la dictadura popular del número o, peor, a su conversión en liderazgo extremo y, al final, en totalitarismo.

Sin embargo, el populismo presenta muchas caras y demasiadas acepciones (Mudde y Rovira, 2014: 377-378; Rovira et al., 2017). Las más sutiles o recurrentes comprenden su visión como discurso (que distingue entre pueblo

2018: 320; vid. 317-340, «IV. El principio democrático y la supremacía de la Constitución»: 4. El poder constituyente totalitario; 5. El ataque totalitario al Estado constitucional). 
ordinario y élites), patología de la democracia (que, en su ataque a los límites del sistema constitucional y representativo, reclama la soberanía absoluta del principio de mayoría), estilo politico singular (apelando a las emociones, con soluciones simplistas a problemas complejos y con una exaltación de las urnas como resolución balsámica de cualquier controversia) y estrategia pública (deliberada forma de ser/estar en política). Pero, a pesar de la confusión en el etiquetado $^{14}$, principalmente negativo, el populismo es, hoy, un significante tan relevante de la política como para acaparar muchos focos mediáticos y cada nueva contienda electoral. Sin embargo, aunque ya hace tiempo abundan estudios sobre el populismo desde distintos ámbitos de conocimiento (ciencias políticas, análisis históricos, filosóficos, etc.), todavía las miradas desde posiciones jurídicas siguen siendo minoritarias (Mudde, 2013: 4-6; Rovira, 2013; Moffitt, 2016: 3; Pinelli, 2011: 5-11; Corrias, 2016: 6-26). Desde esta perspectiva - y para Moffitt-, populista sería aquel que distingue de, manera extrema, entre nosotros, el pueblo — fuente de todo poder y de lo bueno-, y ellos - los enemigos de ese pueblo y depositarios de lo malo, sean de dentro (élites, corruptos, etc.), sean de fuera (inmigrantes, minorías, etc.). Pero su uso peyorativo, para denigrar al adversario político, nos sitúa en una tarima demasiado meritocrática e impoluta, sin llegar a percibir todas las dimensiones de un fenómeno que no se detiene por la mera negatividad de tantos juicios.

Por eso, vistas las dificultades para definir el populismo como ideología, lógica, discurso o estrategia, Moffitt se decanta por observarlo como estilo político (2016: 28 y ss.). Por su parte Vallespín y M. Bascuñán consideran que no estamos ante una ideología, ni dura ni blanda, sino frente a una "lógica política", de "forma de acción política", de "estilo", "retórica" " que viene a llenar el vacío "después del fin de las ideologías»; en definitiva, el renacer populista — teorizado de forma elaborada y estratégica por Laclau y Mouffe— como respuesta a «estos momentos postideológicos» $(2017: 57,67-68)^{15}$.

A pesar de las críticas y sin perjuicio de la diversidad de formas de entender el nuevo populismo, conviene subrayar, por su simplicidad y aceptación,

14 Definición tanto por lo que es (glorificación de la legitimidad del pueblo frente a la deslegitimación del «no-pueblo») como por lo que repudia (sobre todo, elitismo y pluralismo) (Mudde y Rovira, 2013: 494, 500-506; 2017: 7-8).

15 De ahí la definición del propio Laclau, en el prefacio de 2004 a La razón populista: «El populismo es, simplemente, un modo de construir lo político» (2005: 11). Y siguiendo su estela, Luis Alegre: «El objetivo del populismo es siempre construir un pueblo» (2016: 20). O más reciente, en el libro "to Ernesto», se afirma que «Laclau defines populism as a discursive strategy of constructing a political frontier dividing society into two camps and calling for the mobilization of the "underdog" against "those in power" [...]. It is a way of doing politics [...]» (Mouffe, 2018: 10-11). 
la propuesta de Mudde y Rovira. Desde una concepción mínima del populismo, que recorre tiempos y espacios, y dentro del enfoque discursivo, lo definen como delgada ideología que considera a la sociedad fundamentalmente dividida en dos campos homogéneos y antagónicos — de un lado, el pueblo, en su pureza; $y$, de otro, la élite, en su corrupción-, y que, a la vez, estima que la política debe ser la expresión de la voluntad general del pueblo (2017: $5-6)^{16}$. Visiones maniqueas que parasitan otras ideologías y que, sin embargo, tienen - a derecha e izquierda - algo en común: tres significantes distintos (pueblo, élite y voluntad general) y un solo dios verdadero: su totalización singular del poder popular como divinidad democrática (monoteísmo político y moral).

Para Mudde y Rovira, de los tres significantes, dos tienen significados cambiantes y uno permanente: el pueblo y la élite permiten populismos de muy distinto molde, en su determinación de quiénes pertenecen a uno u otra; en cambio, la voluntad general se concibe como la disolución de cada voluntad individual dentro de una volición unificada que, además, permite identificar/ salvaguardar el interés común. La diferenciación que realizan del populismo frente a otras dos ideologías, el elitismo y el pluralismo, subraya sus contornos flexibles: el elitismo comparte con el populismo la frontera bipolar de la sociedad, pero, en vez de dar voz al pueblo/chusma, reivindica las élites/virtuosas; por el contrario, el pluralismo rompe con ese dualismo de buenos y malos, al observar las sociedades como compuestas por individuos y múltiples grupos y, además, desconfía de la existencia de una única voluntad popular (Mudde y Rovira, 2014: 379-380; Held, 2006: 142-165) ${ }^{17}$.

La tentación populista se consuma: presentar a sus adversarios políticos como enemigos públicos, ajenos al pueblo y fuera de su unidad y, en consecuencia, privados de toda legitimidad política ${ }^{18}$. El mayor acento en uno de estos dos antagonistas —élite o extranjeros- determinará básicamente la discriminación entre el populismo de izquierdas frente al populismo de derechas, aunque ambos confluirán en su sublimación de la fábula de la voluntad popular y de la reencarnación de su ejercicio.

16 Contra la definición del populismo como ideología, Aslanidis (2016: 88-104).

17 "Contrary to Schumpeter's view that democratic politics is steered ultimately by competing elites, Dahl (in common with many other pluralists) insisted that it is anchored to a value consensus that lays down the parameters of political life» (Held, 2006: 164).

18 Como corolario a los posicionamientos doctrinales señalados, «el populismo es mejor entendido como una estrategia política para llegar al poder y gobernar y como una lógica política que genera identidades populares», "transformando a los rivales en enemigos» (De la Torre, 2017: 43, 156). 
La construcción del pueblo, propia del populismo, se hace, así, de manera radicalmente contrapuesta: para el populista de derechas, frente a la ola de fuera que busca un dentro, la xenofobia y la negación del extranjero/migrante o, en todo caso, del que no se asimila a su nación atávica y patrimonial; para el populismo de la izquierda, el retorno de la soberanía popular, rechazando las élites - los poderosos y opresores- y excluyéndoles del pueblo, tan inmaculado, que debe renacer y purificarse ${ }^{19}$. Sin embargo, de poco sirve desacreditar el populismo como trastorno de la democracia sin analizar el porqué de su actual fortuna (Akkerman, 2003: 147-159), tal y como demuestra el favor popular en tantos países y no solo a ambos lados del Atlántico.

Por ello es imprescindible discernir las raíces doctrinales de una forma de entender la democracia que reconduce la pluralidad de la población con la apelación a la unidad del pueblo y su titularidad extrema del poder. Y aquí, el populismo de Laclau (2005), en su identificación con la política, cobra todo su relieve: no estamos ante el reflejo de algo preexistente llamado pueblo, sino que la propia acción política es constitutiva de ese pueblo. Es decir, la política y el populismo se insertan en el proceso de construcción de identidades colectivas y de lucha discursiva estratégica por la hegemonía. Se renuncia al marxismo de la guerra de clases y reaparece como posmarxismo en la batalla política existencial (Howarth, 2015) ${ }^{20}$ : la construcción hegemónica de la parte triunfante en su identificación con el pueblo/todo, detentador del poder (de la pluralidad a la unidad y, al mismo tiempo, de la parte al todo).

La indeterminación del sujeto colectivo llamado pueblo solo puede ser formada con una representación que haga visible lo ausente. En su identificación,

19 Siguiendo a Chantal Mouffe (2014; 2016b; 2018), la distinción entre populismos a derecha e izquierda la determina su singularización del enemigo. La política es conflicto, y si, incluso en democracia, la clave no es el consenso a lo Rawls o Habermas, sino la resolución de ese conflicto, la confrontación entre populismos se materializa en «los otros»: básicamente, para la derecha, los inmigrantes; y, principalmente, para la izquierda, la oligarquía, la casta, en fin, las élites (Wodak, 2015); aunque contra el establishment parecen estar todos (a pesar de la extracción desde posiciones dominantes de muchos de sus líderes).

20 Vid. la crítica de Carlos De Cabo (2017: 97) por este abandono de la categoría de "clase» y otros conceptos marxistas, mediante sustitutorios, que denomina, «insignificantes» en los trabajos de Negri («multitud») o Laclau («pueblo»; vid. su defensa, junto con Mouffe, ya en Hegemony and Socialist Strategy, 1985, por la ceguera esencialista de la izquierda —-marxista y socialdemócrata — para entender e integrar los movimientos emergentes: feminismo, antirracismo, medio ambiente, etc.; Mouffe, 2018: 1-2; y también cabe analizar las contradicciones de su "Anti-Essentialist Approach»: 87-93). 
Laclau convierte toda acción política en populismo (Arditi, 2010: 488-497; Thomassen, 2016: 161-176). La unificación simbólica que, para la formación popular, se produce a través de la persona que lo lidera le permite combinar normalidad y excepcionalidad y, con ello, vincular a cada individuo con su pueblo.

La misión del populista queda patentada: hacer presente al pueblo interpretando sus aspiraciones y determinando su voluntad. Con el empoderamiento ciudadano como excusa, la concepción democrática reniega de su adjetivación básicamente representativa y pluralista para (re)buscar, desde la identificación del líder con el pueblo, en los mecanismos de la participación directa y/o plebiscitaria (Moffitt, 2016: 95-101, 41-42, 49) ${ }^{21}$. La construcción del pueblo, propugnada por los populismos, tal y como predica Laclau, recuerda la elucubración nacional de Benedict Anderson: comunidad imaginada como articulación mental en eterno proceso de (re)edificación, donde los autoidentificados con ese pueblo/nación definen su ontología colectiva más monista y excluyente (Wodak, 2015: 77). Escondiendo o encumbrando la resurrección de las naciones, el populismo aclama a su renovado monoteísmo: el pueblo, aunque se idealice desde el presente en su irreductible pureza, recorre un proceso atemporal de perfección con su poder omnipotente.

El Schmitt más defenestrado se ríe de nosotros como paradigma imprescindible que, escorado - a derecha o a izquierda-, permite una lectura de lo político tan condenada por la historia como contaminante de la democracia (Laclau, 2014: 209). Vacío político, crisis orgánica y demandas insatisfechas se retroalimentan para aupar al populismo desde una quiebra económica y financiera que catapulta la ruptura institucional. Pero ni la crisis se supera ni las demandas se satisfacen. Solo el vacío político se colma como disolución del individuo en el líder y comunión de todos en uno. Impugnando la fórmula liberal de la democracia representativa y su adhesión al Estado constitucional de derecho y al viejo sistema de partidos, el populismo - aunque consiente el régimen electoral y su legitimidad aritmética- se revuelve contra la representación institucionalizada y propugna más y más técnicas directas de participación popular y/o aclamación colectiva.

$\mathrm{Si}$, en el liberalismo, primero estaban la persona y sus derechos, en el populismo lo fundamental es la subsunción del individuo a la comunidad en construcción (Zanatta, 2015: 39-40). De ahí a la visión de Verstrynge hay un paso, dado por demasiados: «Para el populismo el Pueblo es, en efecto, "Dios es su país”. Su voluntad es determinante, absoluta, sin paliativos» (2017: 87).

21 "Like many other neo-liberals, Hayek made it clear that if democracy means "the unrestricted will of the majority" he should not be counted as a democrat» (Held, 2006: 204). 
Puro monoteísmo político en su traslación de la legitimidad divina al pueblo, como sujeto volitivo y sin control.

Ante tamaña obscenidad totalitaria, mejor analizar las doctrinas más acabadas sobre el populismo para decretar su amistad o enemistad con la democracia constitucional (Moffitt, 2015; Plattner, 2010: 81-92). Pero, desde el estigma identitario y la ruptura social, tampoco nos convence Laclau con su razón populista (2005). Significantes vacíos y flotantes, relaciones equivalenciales y luchas hegemónicas, antagonismos y fronteras, en definitiva, lenguaje para iniciados del que subyace la identificación del populismo como articulación política desde el choque entre homogeneidad y heterogeneidades y que nos relega a una construcción popular tan sesgada como falaz. Sin la brillantez de Carl Schmitt y carente de su elixir embriagador, Laclau reivindica el populismo - en su confusión con una forma de construcción de lo político en lucha por la hegemonía - de una manera tan acaparadora como para hacer populista a cualquiera: «No existe ninguna intervención política que no sea hasta cierto punto populista». Lo que no empaña que, desde sus ajustes de significantes — con o sin significado-, pueda conceder el marchamo de más populista a unos («discursos de ruptura que tienden a dividir lo social en dos campos») para arrebatárselo al resto («discursos más institucionalizados», 2005: 195$)^{22}$.

La mentira schmittiana, desde la democracia de identidad a la necesidad práctica de la representación más totalizante ${ }^{23}$, se convierte en deconstrucción democrática: el pueblo no puede existir «sin el funcionamiento de los mecanismos de representación» (Laclau, 2005: 204) ${ }^{24}$. Se sustituye la exigencia de homogeneidad nacional por una ficción todavía más lacerante, la constante recreación del significante pueblo: de abajo-arriba, los representados en construcción como pueblo a través de los representantes; y, de arriba-abajo, el representante definiendo a sus representados y galvanizando al pueblo. Desde la heterogeneidad de la masa de individuos aislados a la homogeneidad popular: doble movimiento — de representados hacia el representante, y de este a

22 La etiqueta populista se refuerza con la dicotomía institucionalización y ruptura, siendo los actores políticos más sistémicos los menos populistas, frente a los constructores de nueva hegemonía y, por ello, menos institucionalizados, los rupturistas que copan el cetro de los más auténticamente populistas.

$23 \mathrm{Y}$, de ahí, a su conversión en democracia plebiscitaria con la representación más extrema, $y$, en la etapa nazi, con el principio del poder omnipotente del führer como defensor/creador del derecho desde la nada: "The foundation of law, as Schmitt recognized, was no longer ratio but voluntas, now conceived as "the will of the führer"» (Kennedy, 2004: 169).

24 Vid. también la apología de la representación en Mouffe, 2018: 53-56. 
aquellos- que convierte, con la parte tomada por el todo, la pluralidad en unidad. La respuesta no se hace esperar: de la encarnación total del poder de los reyes absolutos saltamos al vacío de poder, llenado por la representación, o, mejor, por su(s) líder(es) ${ }^{25}$.

Frente al modelo deliberativo de Rawls o Habermas (Held, 2006: 236$238)^{26}$, la relación contingente entre liberalismo y democracia, en Mouffe (2000), sería esa articulación histórica que posibilita a Laclau volver a una concepción procedimentalista de la democracia como construcción popular y soberanía absoluta, desvinculada del individuo, sus derechos y libertades ${ }^{27}$. El significante pueblo sublima lo colectivo subsumiendo al individuo en su seno, pero siempre manteniendo su encarnación, es decir, el representante/ líder que forma, con su presencia, lo informe: el pueblo representado. Sin vacío no hay pueblo ni democracia, afirma Laclau ${ }^{28}$, y, acto seguido, nos arroja por un precipicio mucho más peligroso que el vacío mismo: la necesidad de colmarlo. Y cuando el que lo llena es el líder, la democracia — con esto- deja de serlo.

Pero que nuestra definición democrática se vincule al derecho no significa que tratemos «meramente con los aspectos jurídicos, formales de la democracia», olvidando la noción de politeia (Ryan, 2012: 97-99) en cuanto "forma de vida política de la comunidad», de la cual, según Laclau, «los aspectos constitucionales representan sólo una cristalización formal» (2005: 213-214). Ni la democracia debe ponderar únicamente sus aspectos formales, ni el derecho y lo constitucional es simple determinación de lo jurídico, desvinculando de la política lo material y existencial. Un Estado constitucional que merezca el calificativo de democrático precisa definir su sustrato intangible para no cegar a la justicia, o, peor, asesinarla.

De ahí el papel de la constitución en la delimitación no solo de los procedimientos democráticos sino de los derechos y fines a respetar y desarrollar.

25 «La conclusión es clara: toda identidad popular tiene una estructura interna que es esencialmente representativa»; "Entre la encarnación total y la vacuidad total existe una graduación de situaciones que involucran encarnaciones parciales. Y éstas son, precisamente, las formas que toman las prácticas hegemónicas» (Laclau, 2005: 205, 210). Meritorio fue teorizar condiciones ideales y velos «de ignorantes», pero ni Habermas ni Rawls lograron bajar de su pedestal para decirnos cómo hacer las cosas en el mundo real de la política, que tampoco por ser democrática abandona su crudeza.

27 Para Saffon y Urbinati (2013: 448-450), la concepción de la democracia como búsqueda de la verdad falla por su exceso de racionalismo; en cambio, la versión populista fracasa por su exaltado irracionalismo. ¿Bienvenidas las mediaciones? «Sin la producción de vacuidad no hay pueblo, no hay populismo, pero tampoco hay democracia» (Laclau, 2005: 213). 
Haciendo de la vacuidad y la plenitud términos sinónimos, como proclama Laclau, no se completa — mágicamente— ningún vacío, sino que se hace más hondo el hueco de un significante que se llena, demagógicamente, con liderazgos totalizantes. La relación vacuidad y plenitud como experiencia religiosa unidireccional: el significante vacío consigue su plenitud con la personificación de su mesías redentor, el líder indiscutible de esa fuerza hegemónica.

La pulsión populista convertida en una construcción del pueblo que lo arroja a la esclavitud: disolución del individuo en el líder que encarna el ser y decidir de la comunidad política. Pero, en democracia, la existencia de un sujeto político llamado pueblo se presupone y acoge como dada. Por ello, lo que hará más democrático al poder no será solo el quién (pueblo y procedimientos), sino el cómo (objeto, valores y derechos). No es que la democracia pueda combinarse con la «defensa de los derechos humanos», tal y como argumenta Laclau (2005: 215), sino que únicamente se realiza y perfecciona en su protección y desarrollo.

El gran error del populismo es su constante apelación al pueblo como sujeto en construcción, desvirtuando, así, la propia definición de la democracia. Si democracia es gobierno del pueblo, este — por muy dinámico que se estime y muy constante su transformación - ya es sujeto construido. Por el contrario, si el pueblo no se concibe como dado, se está defendiendo su creación como nuevo actor «a partir de una pluralidad de elementos heterogéneos» (ibid.: 278) ${ }^{29}$, es decir, se estará negando la propia democracia, ya que esta precisa del pueblo como entidad preexistente que gobierna. Más aún, la asimetría entre la comunidad como un todo frente a los que se erigen en sus portavoces, siempre una parte, confirma su final: esa misma parte, los que dicen encarnar la construcción popular, se hace pasar por el todo.

Laclau atribuye "rol constitutivo» a la "heterogeneidad social», modificando el papel constituyente que Schmitt otorgó a la homogeneidad nacionalizada: la lógica de la construcción popular como sinrazón populista (ibid: 277-278). El oxímoron de esta arquitectura del pueblo inunda toda redención populista. No hay ejemplo más ilustrativo de metonimia que completar una palabra con otra de significado divergente: la sinécdoque de "una parte que es el todo». Si esa parte (plebs) se identifica con el todo (populus) y la resuelves

29 Por mucho que Laclau diga que «la heterogeneidad esencial» está «en la base de toda identidad populista» y que no puede ser reemplazada por una «unidad homogénea» (2005: 259), la articulación representativa del populismo conduce a la mayor de las unidades homogeneizadoras: el líder, no carismático a lo Weber, ni siquiera teológico — pero secularizado - a lo Schmitt, sino divinizado o "por la gracia de Dios», tal y como nos muestran tantos totalitarismos. 
con el líder que encarna al pueblo, la contradicción se ha convertido en fábula política para abducidos, tan crédulos como para disolver su proyección colectiva en el representante más parasitario. No cabe parcialidad convertida -a través de la lógica hegemónica - en «una totalidad imposible». Se trata de reconocer la pluralidad política que todo pueblo presenta para buscar la mejor articulación de sus mayorías, desechando esos métodos de construcción popular que pervierten el sentido de la democracia, negando su definición etimológica y falseando su realización. El pueblo, en democracia, no tiene que emerger como actor histórico: siempre será el sujeto actuante de su propia hagiografía. Pero Laclau confunde esta emergencia popular con lo que tradicionalmente se ha llamado revolución; la ruptura que supone el paso de un orden a otro, desde la destrucción del anterior (ibid.: 279, 281, 283-284).

De la articulación de demandas sociales no deviene como resultante - tal y como nos quiere hacer creer Laclau al cierre de su obra (2005: 310) — ninguna entidad colectiva, y menos aún el pueblo como tal. En democracia el pueblo ya existe, y lo que se persigue es demostrar las formas de ejercicio del poder que ostenta. No se trata de contrastar luchas hegemónicas para la construcción de un sujeto previamente concebido como inexistente que se define: bien como contingente y siempre determinado desde la frontera con el enemigo y el antagonismo de unos y otros, o bien desde la identificación de la parte con el todo, despreciando cualquier otra forma de expresión y negando su carácter popular. Los populistas nos arengan con tanta voluntad popular y tanto empoderamiento de la ciudadanía, que — en vez de aglutinar consensos mayoritarios - presentan como tales lo que no son sino decisiones de su(s) líder(es) mesiánico $(s)^{30}$. La política siempre envuelve pasiones y antagonismos, hegemonías y coacciones, en definitiva —y parafraseando al mejor Schmitt—, apropiación, partición y distribución/consumo del poder. Por ello, no puede nunca reconducirse a la razón ${ }^{31}$; pero una cosa es reconocer esto y otra, caer en su tensión más determinista y creer, con su reverso, que la irracionalidad es la lógica política (Thomassen, 2016: 164-170).

El populismo de izquierdas reduce la política a la lucha del bien contra el mal, de ángeles plebeyos contra demonios palaciegos, en una construcción con Laclau y Mouffe - de identidades colectivas desde significantes vacíos y cadenas de equivalencias que simplifican lo complejo en dicotomías antagónicas y confunden, con tropos falseadores, el todo (pueblo) con la parte (los nuestros a los que encarna el líder). Pero esto no significa que debamos plagarnos a

30 «Like Carl Schmitt, Laclau regards representation essentially as a strategy for creating a collective under a single leadership" (Saffon y Urbinati, 2013: 453).

31 «No somos razón pura, eso es todo» (Alegre, 2016: 21). 
esta definición de lo político y desconocer su complejidad, sucumbiendo a la confrontación amigo/enemigo y totalizando lo popular. Incluso Schmitt repudió su cerrazón estatalista y se avino a nuevas concepciones y órdenes político-jurídicos, desde la conformación planetaria del Nomos de la Tierra (1950). Y de poco sirve recordar que Mouffe (2012: 27), en su crítica a Habermas, no se congratula de la existencia del antagonismo; tampoco lo alaba expresamente Schmitt, aunque su silencio no le exonere de culpa. El problema, tanto en el original alemán como su intento de domesticación agonística por la pensadora belga, es que, aun transformando el enemigo en adversario y la democracia de identidad en radical (Martin, 2014; Mouffe, 2013; 2018: 39-57), se continúa simplificando lo político de manera tan dual y burda como para imposibilitar resolver la paradoja de la democracia, al exacerbar las fronteras y renunciar a la hermandad humana con una igualdad nacional y/o popular excluyente ${ }^{32}$ : un pluriverso, de nuevo, tan estatalizado y cateto como para renegar de los valores universales y de la lucha por la democratización mundial.

La forma de hacer política que destila el populismo simplifica lo complejo y enfrenta buenos contra malos, dejando la paleta de los colores humanos y de sus identidades yuxtapuestas tan inutilizada como reducida al nosotros contra ellos (Mouffe, 2012: 295). La clave del análisis populista, más que en su concepción como ideología o en su definición como marco discursivo o lógica de actuación política, más que en su determinación formal o en su contenido moral, estriba en la totalización excluyente que expande. Pero, por mucho que se empeñen los movimientos populistas (e, incluso, la ciudadanía en general), la única fuente de legitimidad no puede ser el pueblo en singular y, menos aún, su concepción unívoca como ser homogéneo en su confrontación con el «no-pueblo ${ }^{33}$ » (Mudde y Rovira, 2017: 48).

Desde esta visión dicotómica, la soberanía popular, de un lado, pretende encarar un mayor empoderamiento ciudadano en los asuntos públicos, pero, de otro, y en su último recorrido, conllevará siempre el rechazo a cualquier mecanismo que controle el poder, desdeñando, por tanto, la esencia misma del Estado constitucional y, con ello, la fundamentación material de la democracia. De ahí que los supuestos efectos positivos que pudiera procurar el populismo

32 El agonismo de Mouffe, a pesar de la fundamentación consensual desde unos valores legitimadores, choca abruptamente con su propia definición del populismo (2018: 10-11). Desde una fundamentación pluralista y axiológica de la legitimación de la democracia, el We no puede construir un Nosotros que excluye a una parte de los que ya lo integran.

33 El nos, puro, primigenio y en permanente (re)construcción, frente a un ellos, los que «nos roban» y quiebran vidas o esperanzas. 
para la democracia, presentados por Mudde y Rovira $\left(2017\right.$ : 82-83) ${ }^{34}$, no contrarresten su negatividad: especialmente, el ataque a los derechos de las minorías, a los derechos fundamentales de los individuos y a cualquier límite al poder.

La dictadura de la mayoría desde la soberanía sublimada cercena toda cláusula de intangibilidad de la democracia. Por ello, frente a una posición favorable al populismo que incidiría, únicamente, en un dudoso perfeccionamiento meramente cuantitativo, los efectos perniciosos entran de lleno en la esencia del modelo democrático constitucional, al totalizar y moralizar la política con la alegoría del pueblo y su santidad.

No obstante, este discurso moral maniqueo que impregna a todo populista, independientemente de nuestro parecer, se convierte en el enfoque que manejan cada vez más y más ciudadanos. Por tanto, ya no se trata de afrontar el desafío que supone la presencia, consolidación e, incluso, asalto al poder de movimientos populistas de diferentes espectros, sino la cada vez mayor comprensión populista de la política por amplios sectores de la sociedad (ibid.: 97-100). En particular, desde la crisis económica y la sobreabundancia de casos de corrupción sistémica, la quiebra de la confianza institucional de buena parte de la ciudadanía abona el terreno para una política cada vez más temerosa y simplificada en su comprensión populista.

Desde su engarce con la desafección ciudadana, las pasiones identitarias y la guerra nosotros (los buenos) versus los otros (los malos o, cuanto menos, los que no son "de los nuestros»), el populismo no solo arremete contra elementos liberales o controles jurídicos, sino contra la propia democracia: radicalizando el componente procedimental del gobierno (mayoritario) del pueblo y sin protección efectiva de los derechos del individuo y de las minorías no se está definiendo ninguna democracia que realice tal denominación. La democracia, o se concibe como intangible y de derechos, o no es más que la carcasa cuantitativa de una supuesta unidad popular tan abusiva en su poder teórico como inexistente en su encarnación representada.

\section{EN DEFENSA DE LA DEMOCRACIA INTANGIBLE}

La plasmación del poder popular desde el principio de mayoría y la personificación de todos (el pueblo) en uno (el representante o líder absoluto)

34 Vox a grupos que no se sentían representados, movilización de sectores excluidos y su mayor integración política, capacidad de respuesta del sistema con propuestas diferentes y atención a las demandas sociales, o incrementando la rendición de cuentas y la responsabilidad pública. 
dejan inermes a nuestras democracias. Por esa razón, poco importan nominalismos grandilocuentes y tampoco vale la pena pretender cerrar batallas académicas sobre la definición más afortunada del populismo ${ }^{35}$.

Lo realmente inquietante y sustantivo son las bases comunes de discursos, movimientos o estrategias de muy diverso signo, a ambos lados del espectro político, que tienen esa «lógica» de reconstrucción del pueblo como referente fundante, teologizando el poder, destruyendo el pluralismo, echando la culpa a los otros (el «no-pueblo») y que, también, van expandiéndose por más ámbitos públicos y cada vez son refrendadas electoralmente por más ciudadanos. Por eso, frente a la respuesta ante la anomia politica que describe Villacañas en su definición del pueblo desde el populismo ${ }^{36}$, apostamos por la resolución definitiva de la antinomia constitucional.

Así la contradicción retórica del ordenamiento constitucional español se clarifica con su contenido intangible: por un lado, la fundamentación de lo jurídico en una ontología comunitaria llamada unidad de la nación (poder constituyente del art. 2 CE); por otro, el fundamento del orden político y la paz social en la propia dignidad de la persona, sus derechos inviolables y el respeto a la ley y a los derechos de los demás (minimo intangible del art. $10.1)^{37}$. Con la conversión del poder constituyente en poderes constituidos, la supuesta incoherencia constitucional se disuelve desde la primacía normativa del art. 9.1, como sujeción de todos — ciudadanos y poderes públicosa la Constitución y al resto del ordenamiento, con el máximo emancipador de la promoción de la libertad y la igualdad y la integración estatal en una ordenación internacional que también protege nuestros derechos (arts. 9.2., 10.2 y 93-96 CE).

Sin embargo, cuando habíamos vencido a la paradoja de la definición de la democracia (Mouffe, 1999: 38-52) con la confluencia necesaria - y siempre mejorable - del pilar jurídico/constitucional en la construcción político/

35 Judis considera erróneo buscar una concepción distintiva del populismo cuando no estamos ante un término científico del tipo de la fotosíntesis (2016: 13; también Mouffe estima estéril el debate académico sobre la "verdadera naturaleza» del populismo, 2018: 9). Aunque sí parece inexcusable hacer pedagogía, ante la ciudadanía, sobre la mejor definición de la democracia.

36 «Comunidad construida mediante una operación hegemónica basada en el conflicto, que diferencia en el seno de una unidad nacional o estatal entre amigos/enemigos como salida a la anomia política y fundación de un nuevo orden» (2015: 28).

37 En este sentido la jurisprudencia constitucional nos enseñó que «los derechos fundamentales», en su "vinculación directa entre los individuos y el Estado», «actúan como fundamento de la unidad política sin mediación alguna» (STC 25/1981, de 14 de julio, FJ 5). 
popular, se nos vuelve a presentar en su vertiente más populista: en el anverso, frente a las debilidades democráticas actuales y los miedos/odios ante un mundo mutante, se alzan cada vez más voces que reclaman todo el poder para mi pueblo; en el reverso, su devolución efectiva siempre conllevará la personificación humana en líderes "fuertes» — cada vez con menos frenos y contrapesos- que dicen ser la encarnación popular.

De ahí la confusión entre los teóricos, todos partidarios de la democracia, pero enfrentados cuando se trata de enjuiciar el populismo: unos, observándolo como su empoderamiento radical; otros, como su degeneración totalitaria (Akkerman, 2003; Arditi, 2004; 2007) ${ }^{38}$. Porque la controversia radica en la misma definición de la democracia: para los adalides de su identificación populista, la democracia es - fundamental o únicamente- gobierno ilimitado del pueblo; para los que se oponen a esta renovación de la nomenclatura de la soberanía teológica, la democracia tendría también, junto con su vertiente formal y representativa, una sustantividad material que se resuelve jurídicamente como límite al poder (constituyente) y controles entre poderes (constituidos), desde la dignidad de la persona y los derechos de minorías e individuos ${ }^{39}$.

38 Como afirman Abst y Rummens, el populismo, en su cohabitación con la democracia, también proclamaría el gobierno soberano del pueblo, pero, frente a su exacerbación ilimitada, la democracia busca, con su confluencia constitucional, el límite al poder (2007: 405, 419-420).

39 Derechos humanos como protección universal frente a los abusos. Pero una democracia identificada con el poder absoluto arremete contra los derechos humanos y sus garantías (Roth, 2017). Por eso Ferrajoli subraya la contradicción con la idea misma de democracia de la soberanía ilimitada: «Conforme a esta redefinición de la soberanía popular y de la relación entre democracia y pueblo, podemos pues afirmar que el requisito formal y procedimental de las decisiones por mayoría, si bien es necesario para anclar, aun indirectamente, el poder político en sus destinatarios, no es suficiente para definir la democracia» (2011: 15). Se consolida la limitación del poder soberano del pueblo en cuanto prohibiciones y obligaciones impuestas a los poderes de la mayoría, como garantías y perfeccionamiento de los derechos fundamentales, entendidos, como fragmentos de soberanía popular. Los derechos fundamentales no son suprimibles ni reducibles por el poder de la mayoría; de ahí que se hallen sustraídos al poder de revisión constitucional. Además, para el jurista italiano, las amenazas más graves a la democracia constitucional provienen de «dos poderosas ideologías de legitimación del poder: la idea de la omnipotencia de las mayorías políticas y la idea de la libertad de mercado como nueva Grundnorm del actual orden globalizado» (2011: 14, 43, 47-51, cita: 71). A lo que añadimos, aquí, el fraude de reconducir la democracia (con o sin apoyo electoral) al líder total que decide cuál es la voluntad popular (con o sin refrendo plebiscitario binario). 
La moralina ontológica del populismo y su recurrente deslegitimación del adversario se convierten en manifiesta distorsión, no ya de la realidad, sino de la propia democracia, negando - en su extremismo excluyente y supremacista - el calificativo de pueblo a todos aquellos que queden fuera de su identificación como de los nuestros. Tanta democracia de identidad, tanta igualación sustantiva entre gobernantes y gobernados, para articular una analogía que ni es dada ni natural, sino pensada como presupuesta, y, por ello, solo factible —en su realización artificiosa — desde la representación más absoluta de un líder que presenta, con su actuación volitiva, la inexistente voluntad y homogeneidad del pueblo (Mouffe, 2000: 54-55; Abst y Rummens, 2007: 421).

Sin embargo, la condena del populismo como «corrupción del pueblo como sujeto político» (Lasalle, 2017: 26) no determina las causas que han forjado su irrupción y fomentado sus conquistas. El pueblo, «cuando se desvía del respeto a la formalidad de la ley y decide hacer su santa voluntad» (ibid.: 25), desprecia todo límite al poder y, con ello, la propia esencia de la democracia. Pero la réplica a Lassalle, expuesta por Errejón, sigue enrocada — con Mouffe (2018: 14) — en la supuesta dicotomía democrática entre el principio liberal y la tradición de la soberanía popular. Para el cofundador de Podemos, el pueblo deja de vincularse con la voluntad general, al modo rousseauniano, y deviene en mero relato o meta compartida para determinar la ordenación social. Desde aquí, la posición de Lasalle, con su crítica a la prelación de la esencia popular de la democracia, se convierte —en su enfrentamiento con la visión populista de izquierdas - no ya en la batalla intelectual más importante del momento (Errejón, 2017), sino, más bien, en la tercera guerra mundial que definirá —en los próximos años- nuestro sistema de convivencia y la pervivencia $-\mathrm{O}$ no- de la democracia ${ }^{40}$.

Declaradas las hostilidades, observar al populismo como una tara o patología de la democracia no ayuda, según Rovira, a discernir el porqué de su crecimiento (2013: 1-3). Pero, aunque mantener la tradicional perspectiva negativa del populismo no sirva para comprender su bonanza (la América de Trump, los Gobiernos europeos - de o con populistas- por doquier, el euroescepticismo estatalista, el brexit, el independentismo catalán y, en definitiva, Vox populi, vox dei), sí que nos coloca ante un absolutismo manipulador de la democracia, en cuanto voluntad sin límites del pueblo y dicotomía social con la reconstrucción de identidades en colisión

40 ¿De la explosión populista a la implosión de la democracia? "The question now is whether this populist moment will turn into a populist age — and cast the very survival of liberal democracy in doubt» (Mounk, 2018: 3). La cursiva es nuestra. 
por la hegemonía política ${ }^{41}$. Sin embargo, por muy rupturista que sea la quiebra, por muy revolucionaria que sea la fractura, siempre subsiste parte del derecho, de su ordenación e institucionalización. A pesar del empeño populista y su asentimiento cada vez más generalizado, la respuesta a la fundamentación normativa no la puede dar únicamente un acto constituyente del poder soberano, entendido como eterno e ilimitado, sino, primero, su comprensión histórico-temporal (referéndum constitucional), después, su proyección democrática actual (legitimación de las instituciones y la defensa constitucional como poder - ya constituido- en funciones constituyentes) y, finalmente, su anclaje en un mundo, también jurídico, que delimita la soberanía de los Estados (ius cogens).

Así, frente a la proximidad a Schmitt — in the Name of the People (Errejón y Mouffe, 2016)—, desde la izquierda populista (Specter, 2016: 426-476), continua siendo mucho más valioso recuperar a Lefort o a Kelsen: el filósofo francés por su comprensión del pueblo como pluralidad de individuos y la democracia como espacio vacío, a ocupar temporalmente, que pertenece a todos y a nadie, pero que en ningún caso puede confundirse con el totalitarismo (Lefort, 1988, 2014); el fundador de la Reine Rechtslehre por su asunción de los derechos de las minorías como valor esencial de la democracia (Kelsen, 2009), a pesar de una visión puramente formal que tiene que revisarse y, ante el engaño populista, con el subrayado de la cláusula constitucional intangible como límite al poder y garantía de derechos (Corrias, 2016: 20-25; Sanz, 2013: 136-145; 2018: 32-33). Y, en ambos casos, siempre desde una definición de la democracia que concibe al pueblo como dado, pero también limitado, es decir, como engarce de la autodeterminación colectiva con una dimensión intangible que protege al ciudadano, su libertad y sus derechos, y que, además, integra el Estado en la ordenación internacional ${ }^{42}$.

41 La proclamación del lenguaje populista como ontológicamente democrático, al definir el pueblo como soberano y, por ello, con voluntad ilimitada, confirmaría su renuncia al constitucionalismo, en cuanto límite jurídico al ejercicio del poder político y, por tanto, su abandono de la propia democracia o, peor aún, su deriva totalitaria (Ramírez, 2015: 47-49).

42 Más que hablar, con Held, de «legal democracy» (2006: 207) con su gobierno de la mayoría delimitado por el imperio de la ley, reforcemos la determinación de la democracia como imperio constitucional, es decir, por la forma y contenidos insertos en la norma suprema, única atribuible al poder constituyente en su manifestación histórica mediante el referéndum de ratificación y, en su actualización, a través de la reforma/revisión constitucional. Simplificando, según Held (2006: 231), la historia de la democracia puede ser leída de dos maneras: celebración, por la superación de la arbitrariedad, o miedo a la conquista del poder por la masa. Paradoja entre la celebración y el miedo que 
No estamos ante ninguna crisis existencial de la democracia, sino ante una nueva revolución doctrinal y política sobre cómo la definimos y cuál es su mejor plasmación ${ }^{43}$. Y las alternativas siguen siendo, básicamente, dos: o, con la exaltación estatal de los populismos, radicalizamos su concepción desde la soberanía popular como voluntad ilimitada hecha decisión por su/s (re)presentante/s; o, con la conversión del poder constituyente en primacía constitucional, limitamos - formal y materialmente - todos los poderes ya constituidos e, incluso, la revisión de la constitución por un poder soberano también constreñido internacionalmente. Solo vinculada al mundo y a una ordenación internacional que también cuenta con límites imperativos al ejercicio del poder de los Estados (ius cogens), la democracia —adjetivada como intangible y siempre, en mayor o menor medida, militante ${ }^{44}$ — podrá seguir protegiendo los derechos de las personas y las minorías ${ }^{45}$. El dilema del presente tiene ya sus prisioneros, o salvamos la democracia constitucional de la nueva totalización popular del poder, o con ella se hundirán nuestro(s) derecho(s).

En definitiva, el desarrollo de una «sociedad democrática avanzada» (preámbulo $\mathrm{CE}$ ) no puede circunscribirse a un proceso de democratización estatalizado, residenciando todo el poder en un único pueblo. La democratización

solo puede equilibrarse desde una concepción que, al tiempo que proclama el triunfo del poder popular, lo somete - formal y sustancialmente- a las prescripciones de una constitución estatal anclada en el mundo del derecho internacional y su ius cogens. La mera forma, de mínimos, nos devuelve a Schumpeter; de máximos, nos arrastra a Schmitt y a su recuperación populista; de ahí nuestra apuesta por la vinculación democrática del quién y el cómo, desde —al menos - un mínimo intangible no accesible al poder (de ninguna mayoría) popular. Aunque oponerse a la máxima de «todo el poder por y para el pueblo» necesita, en la presente desafección ciudadana, mucha pedagogía política.

Para el análisis del concepto de democracia en el siglo xx, vid. Abellán, 2011: 249294, con su recorrido desde la democracia como método de selección de los gobernantes (Weber, Kelsen, Schumpeter, Ortega y Gasset) hasta la democracia deliberativa (Habermas, Bachrach), pasando por la democracia de los pluralistas (Robert Dahl), entre otras visiones. Y, como descripción actual de la crisis de la democracia liberal, vid., Mounk, 2018: 23-131: «1. Democracy without Rights»; «2. Rights without Democracy»; «3. Democracy Is Deconsolidating».

44 Ver el art. 27.2 CE y su carácter militante expreso, con una educación que tendrá por objeto el desarrollo humano «en el respeto a los principios democráticos de convivencia $\mathrm{y}$ a los derechos y libertades fundamentales».

45 En este sentido, Ferrajoli subraya la universalidad de los derechos fundamentales con la siguiente sentencia: "Hacen a cada persona un individuo diferente de todos los demás y de cada individuo una persona igual a todas las demás» (2011: 58). 
debe conjugar, al menos, tres niveles de realización: primero, el del ser humano, por el mero hecho de serlo (derechos universales desde la dignidad de la persona); segundo, la proyección colectiva (el pueblo formando su Estado, con su institucionalización territorial, distribución del poder y ciudadanía multinivel), y tercero, la ordenación global (integración de ese Estado en un sistema internacional —con sus límites/concurrencias de soberanía/s— que completa el progreso democratizador volviendo al ser humano y a su protección inalienable). No vale ignorar cualquier de estos vectores y enrocarse en uno, despreciando el resto.

La democracia debe rechazar - de una vez por todas - su monismo nacional o populista y, desde la autodeterminación del ser humano, o se realiza en un mundo que necesitamos y nos necesita o quedará — una vez másabandonada a su (mala) suerte.

\section{Bibliografía}

Abellán, J. (2011). Democracia. Madrid: Alianza.

Abst, K. y Rummens, S. (2007). Populism versus Democracy. Political Studies, 55, 405-424. Disponible en: https://doi.org/10.1111/j.1467-9248.2007.00657.x.

Akkerman, T. (2003). Populism and Democracy: Challenge or Pathology? Acta Politica, 38, 147-159. Disponible en: https://doi.org/10.1057/palgrave.ap.5500021.

Alegre, L. (2016). Prólogo. En C. Fernández Liria. En defensa del populismo. Madrid: Catarata. Arditi, B. (2004). El populismo como espectro de la democracia: una respuesta a Canovan. Political Studies, 52 (1), 135-143. Disponible en: https://doi.org/10.1111/j.14679248.2004.00468.x.

- (2007). Politics on the Edges of Liberalism: Difference, Populism, Revolution, Agitation. Edinburgh: Edinburgh University Press.

- (2010). Review Essay: Populism Is Hegemony Is Politics? On Ernesto Laclau's "On Populist Reason". Constellations, 17 (3), 488-97. Disponible en: https://doi.org/10.1111/ j.1467-8675.2010.00587.x.

Aslanidis, P. (2016). Is Populism an Ideology? Political Studies, 64, 88-104. Disponible en: https://doi.org/10.1111/1467-9248.12224.

Canovan, M. (1981). Populism. London: Junction Books.

- (1999). Trust the People! Populism and the Two Faces of Democracy. Political Studies, 47, 2-16. Disponible en: https://doi.org/10.1111/1467-9248.00184.

- (2005). The People. Cambridge-UK: Polity Press.

Corrias, L. (2016). Populism in a Constitutional Key. European Constitutional Law Review, 12, 6-26. Disponible en: https://doi.org/10.1017/S1574019616000031.

De Cabo, C. (2017). El Común. Las nuevas realidades constituyentes desde la perspectiva del constitucionalismo crítico. Madrid: Trotta.

De la Torre, C. (2017). Populismos. Una inmersión rápida. Barcelona: Tibidabo.

Del Rey, F. y Álvarez, M. (2017). Politicas del odio. Madrid: Tecnos. 
Errejón, Í. (2017). Artillería intelectual contra el populismo. El Pais, 8-9-2017.

Errejón, I. y Mouffe, Ch. (2016). Podemos: In the Name of the People. London: Lawrence and Wishart.

Ferrajoli, L. (2011). Principia iuris. Teoría del derecho y de la democracia, 2. Madrid: Trotta.

Held, D. (2006). Models of Democracy. Cambridge: Polity Press.

Howarth, D. (2015). Ernesto Laclau: Post-Marxim, Populism and Critique. London: Routledge.

Ionescu, G. y Gellner, E. (1969). Populismo. Buenos Aires: Amorrortu.

Judis, J. B. (2016). The Populist Explosion. New York: Columbia Global Report.

Kelsen, H. (2009). De la esencia y valor de la democracia. Oviedo: KRK.

- (2017). Secular Religion. Wien: Springer-Verlag.

Kennedy, E. (2004). Constitutional Failure. Carl Schmitt in Weimar. Durham: Duke University Press. Disponible en: https://doi.org/10.1215/9780822385578.

Krastev, I. (2011). The age of populism: reflections on the self-enmity of democracy. European View, 10 (1), 11-16. Disponible en: https://doi.org/10.1007/s12290-011-0152-8.

Laclau, E. (2005). La razón populista. Madrid: Fondo de Cultura Económica.

- (2014). The Rhetorical Foundations of Society. London: Verso.

Lassalle, J. M. (2017). Contra el populismo. Cartografía de un totalitarismo posmoderno. Barcelona: Debate.

Lefort, C. (1988). Democracy and Political Theory. Minneapolis: University of Minnesota Press.

- (2014). El pueblo y el poder. Buenos Aires: Prometeo.

Martin, J. (2014). Chantal Mouffe: Hegemony, Radical Democracy, and the Political. London: Routledge.

Merkel, W. y Bochsler, D. (2016). Democracy Barometer. Codebook. Version 5. Aarau: Zentrum für Demokratie.

Moffitt, B. (2015). Populism and democracy: friend or foe? The Conversation, 23-4-2015. Disponible en: https://bit.ly/2W7mmC7. Disponible en: https://doi.org/10.11126/stanford/9780804796132.001.0001.

- (2016). The Global Rise of Populism. California: Stanford University Press.

Monedero, J. C. (2017). La democracia agredida. Populismo, posdemocracia y neoliberalismo. Revista Nueva Sociedad, 267, 142-155.

Mouffe, C. (1999). The Challenge of Carl Schmitt. London: Verso.

- (2000). The Democratic Paradox. London: Verso.

- (2012). Dimensiones de democracia radical. Pluralismo, ciudadanía, comunidad. Buenos Aires: Prometeo.

- (2013). Agonistics. London: Verso.

- (2014). Populism Is a Necessity. The European, 2-5-2014. Disponible en: https://bit.ly/ 2FFHaLI.

- (2016a). El momento populista. democraciaAbierta, 21-11-2016. Disponible en: https://bit.ly/2gGJkPJ.

- (2016b). In defence of left-wing populism. The Conversation. Disponible en: https://bit. ly/1TGUaie.

- (2016c). El reto populista. democraciaAbierta, 5-12-2016. Disponible en: https://bit. ly/2T7Glia.

(2018). For a Left Populism. London; New York: Verso. 
Mounk, Y. (2018). The People vs. Democracy. Why Our Freedom Is in Danger and How to Save It. Cambridge, Massachusetts: Harvard University Press. Disponible en: https://doi. org/10.4159/9780674984776.

Mudde, C. (2013). As Populist Friends or Foes of Constitutionalism. The Foundation for Law, Justice and Society. Oxford: University of Oxford.

Mudde, C. y Rovira, C. (2013). Populism. En M. Freeden (ed.). The Oxford Handbook of Political Ideologies (pp. 493-512). Oxford: Oxford University Press.

- (2014). Populism and political Leadership. En R. A. Rhodes y P. T. Hart (eds.). The Oxford Handbook of Political Leadership (pp. 376-388). Oxford: Oxford University Press.

(2017). Populism. New York: Oxford University Press.

Panizza, F. (2009). El populismo como espejo de la democracia. México: Fondo de Cultura Económica.

Pinelli, C. (2011). The Populist Challenge to Constitutional Democracy. European Constitutional Law Review, 7, 5-16. Disponible en: https://doi.org/10.1017/S1574019611100024.

Plattner, M. F. (2010). Populism, pluralism, and liberal democracy. Journal of Democracy, 21 (1), 81-92. Disponible en: https://doi.org/10.1353/jod.0.0154.

Ramírez, A. (2015). La belleza de los monstruos. Barcelona: Bosch.

Rasch, W. (2016). Carl Schmitt's Defense of Democracy. En J. Meierhenrich y O. Simons. The Oxford Handbook of Carl Schmitt (pp. 313-337). New York: Oxford University Press.

Riker, W. H. (1982). Liberalism against Populism. Illinois: Prospect Heights.

Roth, K. (2017). The Dangerous Rise of Populism. En Human Rights Watch. World Report 2017. Disponible en: https://bit.ly/2igNuOF.

Rovira, C. (2013). Populism vs. Constitutionalism? Comparative Perspectives on Contemporary Western Europe, Latin America, and the United States. Oxford: The Foundation for Law, Justice and Society.

Rovira, C. et al. (2017). The Oxford Handbook of Populism. Oxford: Oxford University Press. Ryan, A. (2012). On politics. New York: Liveright Publishing Corporation.

Saffon, M. P. y Urbinati, N. (2013). Procedural Democracy, the Bulwark of Equal Liberty. Political Theory, 4 (3), 441-481. Disponible en: https://doi.org/10.1177/0090591713476872.

Sanz, J. A. (2013). El parlamentarismo en su encrucijada: Schmitt versus Kelsen, o la reivindicación del valor de la democracia. Revista de Estudios Politicos, 162, 113-148.

(2017). De la prohibición de los mercenarios al rule of law de las Empresas Militares y de Seguridad Privadas. En S. Galera y M. Alda (eds.). Construyendo el futuro: conversaciones jurídicas sobre la Globalización (pp. 139-168). Barcelona: Atelier.

(2018). Tensiones territoriales de ruptura y revisión de la Constitución española: en defensa de la democracia intangible en un Estado Federal de Derecho. Temas para el Debate, 281, 32-34.

Sauquillo, J. (2018). La reforma constitucional. Sujetos y limites del poder constituyente. Madrid: Tecnos.

Schmitt, C. (1950). Der Nomos der Erde. Köln: Greven.

Specter, M. G. (2016). What's "Left" in Schmitt? From Aversion to Appropriation in the Contemporary Political Theory. En The Oxford Handbook of Carl Schmitt (pp. 426-476). Oxford: Oxford University Press. 
Stacey, R. (2016). Popular Sovereignty and Revolutionary Constitution-Making. En D. Dyzenhaus y M. Thorburn (eds.). Philosophical Foundations of Constitutional Law (pp. 161178). Oxford: Oxford University Press. Disponible en: https://doi.org/10.1093/ acprof:oso/9780198754527.003.0009.

Taggart, P. (2000). Populism. Birmingham: Open University Press.

Thomassen, L. (2016). Hegemony, populism and democracy: Laclau and Mouffe today (review article). Revista Española de Ciencia Politica, 40, 161-176.

Vallespín, F. y Bascuñán, M. M. (2017). Populismos. Madrid: Alianza Editorial.

Verstrynge, J. (2017). Populismo. El veto de los pueblos. Mataró: El Viejo Topo.

Villacañas, J. L. (2015). Populismo. Madrid: La Huerta Grande.

Wodak, R. (2015). The Politics of Fear. What Right-wing Populist Discourses Mean? London: Sage. Disponible en: https://doi.org/10.4135/9781446270073.

Zanatta, L. (2015). El populismo. Buenos Aires: Katz Editores. 